\title{
Master of Public Health programmes in South Africa: issues and challenges
}

Thembelihle Dlungwane ${ }^{1 *}$, Anna Voce ${ }^{2}$, Ruth Searle ${ }^{3}$ and Fred Stevens ${ }^{4}$

\author{
* Correspondence: \\ dlungwane@ukzn.ac.za \\ ${ }^{1}$ College of Health Sciences, School \\ of Nursing and Public Health, \\ Howard College Campus, University \\ of KwaZulu-Natal, Glenwood, \\ Durban, South Africa \\ Full list of author information is \\ available at the end of the article
}

\begin{abstract}
Background: The demand for highly skilled public health personnel in low- and middle-income countries has been recognised globally. In South Africa, the need to train more public health professionals has been acknowledged. The Human Resource for Health (HRH) Strategy for South Africa includes the establishment of public health units at district and provincial levels. Programmes such as Master of Public Health $(\mathrm{MPH})$ programmes are viewed as essential contributors in equipping health practitioners with adequate public health skills to meet the demands of the health care system. All MPH programmes have been instituted independently; there is no systematic information or comparison of programmes and requirements across institutions. This study aims to establish a baseline on MPH programmes in South Africa in terms of programme characteristics, curriculum, teaching workforce and graduate output.
\end{abstract}

Methods: A mixed method design was implemented. A document analysis and cross-sectional descriptive survey, comprising both quantitative and qualitative data collection, by means of questionnaires, of all MPH programmes active in 2014 was conducted. The MPH programme coordinators of the 10 active programmes were invited to participate in the study via email. Numeric data were summarized in frequency distribution tables. Non-numeric data was captured, collated into one file and thematically analysed.

Results: A total of eight MPH programmes responded to the questionnaire. Most programmes are affiliated to medical schools and provide a wide range of specialisations. The MPH programmes are run by individual universities and tend to have their own quality assurance, validation and assessment procedures with minimal external scrutiny. National core competencies for MPH programmes have not been determined. All programmes are battling to provide an appropriate supply of well-trained public health professionals as a result of drop-out, low throughput and delayed time to completion.

Conclusion: The MPH programmes have consistently graduated MPH candidates, although the numbers differ by institution. The increasing number of enrolments coupled by insufficient teaching personnel and low graduate output are key challenges impacting on the production of public health professionals. Collaboration amongst the MPH programmes, standardization, quality assurance and benchmarking needs considerable attention.

Keywords: Master of Public Health programmes, Schools of public health, South Africa, Human Resources for Health

\section{() Biomed Central}

(c) The Author(s). 2017 Open Access This article is distributed under the terms of the Creative Commons Attribution 4.0 International

(c) The Author(s). 2017 Open Access This article is distributed under the terms of the Creative Commons Attribution 4.0 International
License (http://creativecommons.org/licenses/by/4.0/), which permits unrestricted use, distribution, and reproduction in any medium, provided you give appropriate credit to the original author(s) and the source, provide a link to the Creative Commons license, and indicate if changes were made. The Creative Commons Public Domain Dedication waiver (http://creativecommons.org/ publicdomain/zero/1.0/) applies to the data made available in this article, unless otherwise stated. 


\section{Background}

The rapidly changing global public health context, which includes multiple disease burdens, complex healthcare systems, and challenging socio-economic and political environments, demands corresponding changes in public health responses and competencies [1-3]. Complex public health responses demand highly skilled public health personnel, with the expertise and knowledge to contribute to strengthening health systems for optimal health service provision $[2,4-6]$. However, particularly in low- and middle-income countries, huge discrepancies exist between population health needs, health service provision needs, and the quantity and appropriateness of training of the public health workforce $[7,8]$.

In Africa, in particular, the production of the public health workforce has not kept pace with the need, given the multiple burdens of disease, and specifically the burden imposed by the HIV, AIDS and TB epidemics [8-11]. In most African countries $[2,5,6]$, health systems and health programmes are managed by clinicians with minimal public health training, resulting in poor health service management and ineffective resource allocation [2, 3]. In South Africa, the need to train more public health professionals has been acknowledged [12]. The Human Resources for Health (HRH) Strategy for South Africa includes the establishment of public health units at district and provincial levels [12]. Thus, a substantial investment is needed for training an effective health workforce.

Programmes such as the Master of Public Health (MPH) are viewed as essential contributors to equipping health practitioners to meet the demands of the health system $[13,14]$. With the introduction in South Africa of a re-engineered model of primary healthcare, and a National Health Insurance (NHI), the HRH strategy has called on $\mathrm{MPH}$ programmes to increase the output of MPH graduates in order to ensure effective health service delivery and improved health outcomes [12].

MPH programmes in South Africa are offered mostly at postgraduate level, on a fulltime or part-time basis. The programmes are aimed at equipping various health practitioners from a variety of disciplines, with key public health competencies and with collaborative strategies to address population level risk factors contributing to the global and national burden of disease [15-17]. They train health professionals by drawing on knowledge and skills from a variety of biomedical and social science disciplines to define, assess and ultimately resolve public health problems [2, 18]. In addition, the programmes equip practitioners to become innovative public health professionals with an emphasis on multidisciplinary approaches that apply the latest scientific knowledge [2, 4, 13, 18].

Postgraduate public health training in South Africa originated in medical schools in the 1940s, within departments of community medicine, and was designed as a Master of Medicine, comprising specialised public health training for medical doctors [19]. However, MPH programmes now accommodate students who come from multiple health and social science disciplines [5]. Postgraduate programmes in public health are the most broadly recognised professional postgraduate qualification for leadership positions in health $[12,20]$.

Most MPH programmes in South Africa are based on theoretical training with little or no field experience within the course as compared to most programmes in other African countries $[21,22]$. Despite the leadership expectation of public health 
graduates, there are signs of a disconnection between public health leadership need and public health as taught in the MPH programmes [23]. So, the questions arise as to what is being taught in the different programmes, and what would be required to increase and upgrade the public health workforce. All MPH programmes were instituted independently. There is currently no systematic information on MPH programmes offered by South African universities. This study aims to establish a baseline on MPH programmes in South Africa (SA) in terms of programme characteristics, curriculum, teaching workforce and graduate output.

\section{Methods}

A mixed method research design was applied. Firstly, a cross-sectional descriptive survey consisting of both quantitative and qualitative data collection was implemented of all MPH programmes offered in South Africa and active in 2014. The study did not include programmes that offer a Master of Science or Master of Philosophy in Epidemiology. The MPH programme coordinators of the 10 active programmes were invited to participate in the study via email. Out of the 10 who were invited to participate, 8 responded. Weekly reminders were sent to the non-respondents for a period of 8 weeks. An interviewer-administered questionnaire was completed with each programme coordinator between August 2014 and December 2014. The questionnaire comprised of 20 questions, both closed- and open-ended questions. Data were collected on programme characteristics, curriculum, teaching, workforce and graduate output. The questionnaire was pretested with two academic staff members in one $\mathrm{MPH}$ programme. The numeric data were captured into Microsoft Excel 2003 and exported into SPSS15. Numeric data were summarized in frequency distribution tables. Nonnumeric data was captured, collated into one file and then thematically analysed. Throughput was determined for the cohort of students who enrolled between 2009 and 2011, and graduated between 2012 and 2014.

Secondly, document analysis was conducted of (1) curriculum documentation for each of the MPH programmes and (2) published literature on postgraduate public health training and the public health workforce in SA. Programme coordinators provided curriculum documentation. Published literature was identified through Google Scholar and PubMed (Table 1). Keywords used to search the published literature included "Master of Public Health programmes", "Schools of public health", "South Africa", and "Public Health Workforce". Given that this is a case study for SA, policy and legal documents published by South African (official) professional bodies were included. All articles and documents were written in English. The variables used were MPH programme characteristics, curriculum, teaching workforce and graduate output. The data were analysed using the four predetermined themes: context, programme structure, quality assurance processes and output.

Ethical approval was granted by the University of KwaZulu-Natal Human and Social Sciences Research Ethics Committee (HSS/0561/014D). Informed consent was obtained from all participating MPH programme coordinators.

\section{Results}

The results are presented in four themes, namely context, programme structure, quality assurance processes and output. 
Table 1 List of documents on postgraduate public health training in South Africa

\begin{tabular}{|c|c|c|}
\hline Author & Year & Title \\
\hline African Schools of Public Health Association & 2014 & $\begin{array}{l}\text { Core competencies for a Master in Public Health graduate } \\
\text { in Africa. }\end{array}$ \\
\hline Gear J & 2013 & $\begin{array}{l}\text { Public health in South Africa 1975-89: reflections on a } \\
\text { momentous past. }\end{array}$ \\
\hline Pick W & 2013 & Reflections on Public Health in South Africa, 1993-2002. \\
\hline Hoffman M, Coetzee D, Hodes R, London L & 2012 & $\begin{array}{l}\text { From comprehensive medicine to public health at the } \\
\text { University of Cape Town: a } 40 \text {-year journey. }\end{array}$ \\
\hline Fonn $\mathrm{S}$ & 2011 & $\begin{array}{l}\text { Linking public health training and health systems } \\
\text { development in sub-Saharan Africa: Opportunities for } \\
\text { improvement and collaboration. }\end{array}$ \\
\hline National Department of Health & 2011 & Human Resources for Health South Africa. \\
\hline Alexander L, Igumbor E, Sanders D & 2009 & $\begin{array}{l}\text { Building capacity without disrupting health services: public } \\
\text { health education for Africa through distance learning. }\end{array}$ \\
\hline $\begin{array}{l}\text { Mokwena K, Mokgatle-Nthabu M, } \\
\text { Madiba S, Lewis H, Ntuli-Ngcobo B }\end{array}$ & 2007 & $\begin{array}{l}\text { Training of public health workforce at the National School } \\
\text { of Public Health: meeting Africa's needs. }\end{array}$ \\
\hline $\begin{array}{l}\text { ljsselmuiden C B NT, Duale S, } \\
\text { Tumwesigye N M, Serwadda D }\end{array}$ & 2007 & $\begin{array}{l}\text { Mapping Africa's advanced public health education } \\
\text { capacity-the AfriHealth project. }\end{array}$ \\
\hline Reddy J & 1998 & $\begin{array}{l}\text { Regional consortia, partnerships, mergers and their } \\
\text { implications for the transformation of the South African } \\
\text { higher education system. }\end{array}$ \\
\hline National Department of Health & 1997 & $\begin{array}{l}\text { White Paper for the Transformation of the health system } \\
\text { in South Africa. }\end{array}$ \\
\hline
\end{tabular}

\section{Context}

There are three types of public universities in South Africa: (a) traditional universities $(N=12)$, which offer theoretically oriented university degrees, (b) universities of technology $(N=8)$, which offer vocationally oriented diplomas and degrees, and (c) comprehensive universities, which offer a combination of both types of qualification $(N=6)$. Private universities have emerged in the last 10 years and currently, there are five accredited traditional private universities. $\mathrm{MPH}$ programmes are offered in eight traditional and two comprehensive public universities, whereas only one private institution offers a MPH programme (Table 2).

Table 2 Overview of institutions offering MPH in South Africa

\begin{tabular}{llllll}
\hline Programme number & Public/private & Type of university & Learning strategy & Active/inactive & Province \\
\hline Programme 1 & Public & Traditional & Traditional & Active & Limpopo \\
Programme 2 & Public & Traditional & Blended & Active & Gauteng \\
Programme 3 & Public & Comprehensive & Traditional & Active & Limpopo \\
Programme 4 & Public & Traditional & Traditional & Active & Gauteng \\
Programme 5 & Public & Traditional & Traditional & Active & Gauteng \\
Programme 6 & Public & Traditional & Blended & Active & Western Cape \\
Programme 7 & Public & Traditional & Traditional & Active & Western Cape \\
Programme 8 & Public & Traditional & Traditional & Active & KwaZulu-Natal \\
Programme 9 & Public & Comprehensive & Traditional & Active & Eastern Cape \\
Programme 10 & Public & Traditional & Traditional & Active & Eastern Cape \\
Programme 11 & Private & Traditional & Traditional & Active & Gauteng \\
Programme 12 & Public & Comprehensive & Online & Inactive & Gauteng \\
\hline
\end{tabular}


In terms of geographical location, four programmes are situated in Gauteng, two in the Western Cape, two in the Eastern Cape, two in Limpopo and one in KwaZulu-Natal.

The number of MPH programmes offered in South Africa has grown over the past 25 years, increasing from 3 in 1990 to 10 in 2014. Two universities started offering the MPH programme in 1998, followed by one in 1999, four in 2000, and one in 2006. Five MPH programmes are affiliated to medical schools and three are located within the faculty of health sciences (Table 3 ).

\section{Programme structure}

The number of enrolments per year ranges from 20 to 80 across MPH programmes. All programmes have increased enrolment numbers, in line with the government mandate of the massification of, and increased access to higher education [24]. In the years 2012 to 2014, the number of new applications received by individual MPH programmes per year outnumbered the number of vacancies (Table 3). Applicants are not only from South Africa but from all over Africa and further afield. In order to qualify to enter MPH studies, an applicant must possess at least a four-year bachelor level degree in the social sciences or in the health sciences and, in some instances, 2-3 years of work experience is a prerequisite.

Most of the programmes offer intensive face-to-face lectures at the beginning of the semester. In addition, course material and assignments are provided through online teaching platforms. Most of the programmes are university based with little or no service attachment or field placement. The total number of full-time academic staff across all MPH programmes was 84 (Table 4). The student: staff ratio ranged from 1:7.25 to 1:24.25 across programmes. The number of academic staff with $\mathrm{PhDs}$ is low in some programmes (Table 4).

Most programmes are offered part time. The delivery of the programmes caters for students who are enrolled for postgraduate studies while working. Two programmes are offered via distance education with only initial face-to-face contact during the first semester in the first year. A majority of programmes offers a wide range of specialisations. All programmes comprise both a coursework and a research component. The weighting of coursework compared to research credits varies from institution to institution. However, the coursework and research components have to meet the minimum proportion of credits according to the National Qualifications Framework (NQF).

With regard to the coursework component, the programmes offer a general MPH track as well as specialisation tracks. The common core modules for the general $\mathrm{MPH}$ track are biostatistics and epidemiology. The most common specialisation tracks across programmes are epidemiology, social and behavioural sciences, and health policy and management (Table 2). For the research component, most institutions expect students to complete a mini thesis that comprises at least one third (33\%), and up to one half (50\%), of the total qualification credits (Table 5).

In $\mathrm{SA}$, no consensus has been reached with regard to core competency guidelines for MPH graduates and to date, no universal core competencies have been adopted. [25]. Hence, the curriculum varies from programme to programme. The development of a competency framework was drafted by the African Association of Schools of Public Health in 2014. The current draft was tabled for discussion by relevant stakeholders. The draft outlines that MPH competencies should address the current state of health 


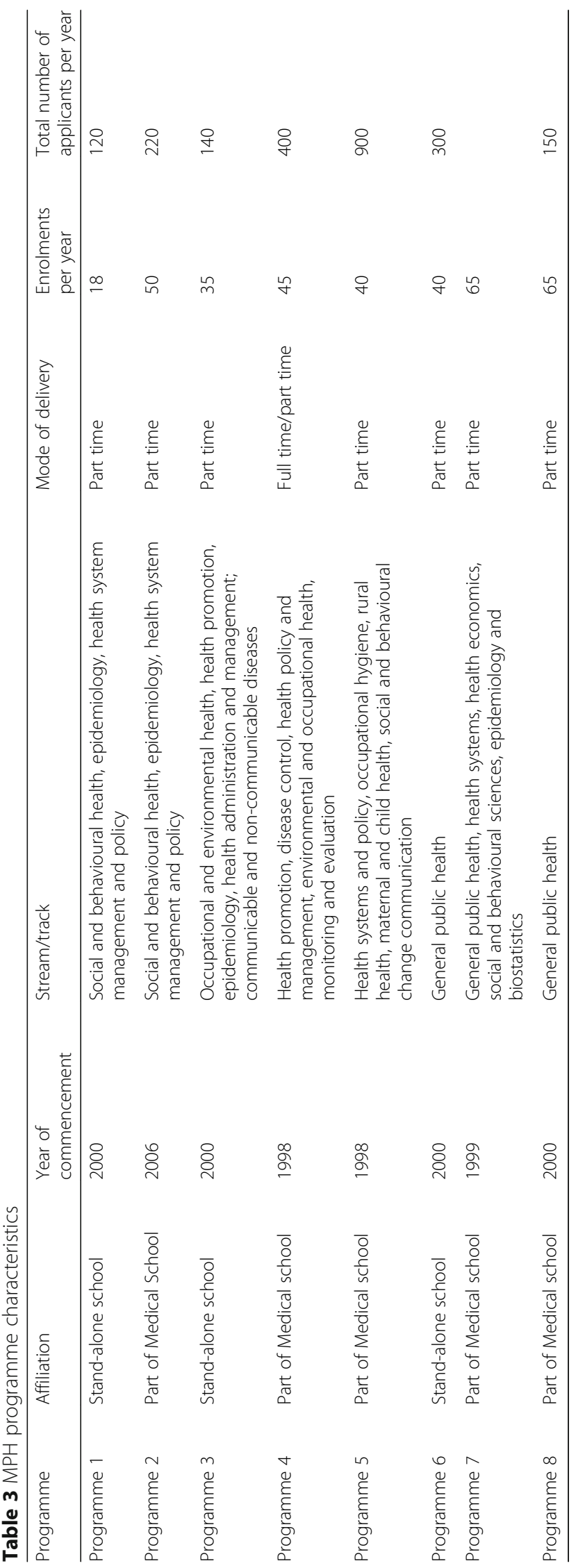


Table 4 Total number of full time academic staff and educational level

\begin{tabular}{lccc}
\hline Institution & No of academic staff & \multicolumn{2}{c}{ Educational level } \\
\cline { 3 - 4 } & & Masters & PhD \\
\hline Programme 1 & 4 & 5 & 1 \\
Programme 2 & 12 & 3 & 7 \\
Programme 3 & 7 & 4 & 4 \\
Programme 4 & 20 & 1 & 3 \\
Programme 5 & 4 & 11 & 11 \\
Programme 6 & 22 & 5 & 10 \\
Programme 7 & 15 & 7 & 3 \\
Programme8 & 10 & 39 & 55 \\
Total & 94 & & \\
\hline
\end{tabular}

systems and burden of disease in Africa which is characterised by epidemics of both communicable and non-communicable diseases [25].

\section{Quality assurance processes}

All Master's programmes in South Africa are guided by the NQF in terms of the minimum number of credits required for the awarding of a master level qualification. The current MPH programmes are run by individual universities, each having their own quality assurance, validation and assessment processes with minimal external scrutiny. Some programme coordinators highlighted the need for an association or quality assurance body to ensure that there is benchmarking and standardization across various programmes. A proposal to establish standards-generating bodies for all programmes was released in 2000, but there has never been one established for public health postgraduate programmes [26].

\section{Outputs}

Over the past 5 years the total number of graduates has steadily increased (Table 6). However, the yearly average throughput for MPH programmes in South Africa ranged from 25 to $60 \%$ for the cohort of students who enrolled between 2009 and 2011, and graduated between 2012 and 2014 (Fig. 1). The peak attrition period in most MPH programmes is on completion of the coursework prior to engaging in the research project.

Table $5 \mathrm{MPH}$ curricula in South Africa

\begin{tabular}{|c|c|c|c|c|c|c|}
\hline Programme & $\begin{array}{l}\text { Credits } \\
\text { required }\end{array}$ & Coursework & $\begin{array}{l}\text { Research } \\
\text { project }\end{array}$ & $\begin{array}{l}\text { Core } \\
\text { modules }\end{array}$ & $\begin{array}{l}\text { Module } \\
\text { offering }\end{array}$ & $\begin{array}{l}\text { Total number of } \\
\text { modules required }\end{array}$ \\
\hline Programme 1 & 200 & $60 \%$ & $40 \%$ & 6 & 8 & 8 \\
\hline Programme 2 & 200 & $50 \%$ & $50 \%$ & 4 & 8 & 8 \\
\hline Programme 3 & 180 & $67 \%$ & $33 \%$ & 3 & 8 & 8 \\
\hline Programme 4 & 240 & $67 \%$ & $33 \%$ & 10 & 51 & 10 \\
\hline Programme 5 & 360 & $50 \%$ & $50 \%$ & 7 & 12 & 6 \\
\hline Programme 6 & 180 & $67 \%$ & $33 \%$ & 6 & 8 & 8 \\
\hline Programme 7 & 180 & $67 \%$ & $33 \%$ & 4 & 25 & 10 \\
\hline Programme 8 & 192 & $50 \%$ & $50 \%$ & 5 & 9 & 6 \\
\hline
\end{tabular}


Table 6 MPH graduates: 2010-2014

\begin{tabular}{llllll}
\hline Institution & 2010 & 2011 & 2012 & 2013 & 2014 \\
\hline Programme 1 & - & - & - & - & - \\
Programme 2 & 27 & 35 & 11 & 24 & 43 \\
Programme 3 & 10 & 6 & 5 & 13 & 4 \\
Programme 4 & 43 & 38 & 32 & 36 & 29 \\
Programme 5 & 14 & 39 & 31 & 19 & 23 \\
Programme 6 & 38 & 42 & 54 & 29 & 26 \\
Programme 7 & 23 & 36 & 32 & 44 & 20 \\
Programme 8 & 11 & 11 & 4 & 12 & 11 \\
\hline
\end{tabular}

The average time to completion amongst MPH students across all programmes is 45 years, as opposed to the minimum 2 years for part-time studies recommended by the South African Qualifications Authority (SAQA). Drop-out and delays are attributed to the research project challenges experienced by students. Challenges experienced in the research project identified by programme coordinators include inadequate academic writing skills among students and poor supervisor-student relationships.

\section{Discussion}

There are limited number of MPH training institutions in SA. Of the 20 traditional and comprehensive public universities, the $\mathrm{MPH}$ is only offered in 10 institutions across the country. The training is concentrated in few provinces. For a population of 56 million in SA, public health training is not widely distributed and public health capacity is concentrated in a few urban-based academic institutions. However, this is not unique to SA. Several low- and middle-income countries (LMICs) are faced with inadequate numbers of educational institutions and geographical maldistribution of MPH training programmes $[6,7,27-30]$.

Postgraduate public health training in SA dates back to the 1940s, where multidisciplinary training was offered by the Institute for Family and Community Health (IFCH) $[31,32]$. The institute was later closed due to the lack of political support [31, 32]. In most medical schools, postgraduate public health was offered for medical doctors only, within departments of community medicine, which later evolved into departments of community health $[6,33]$.

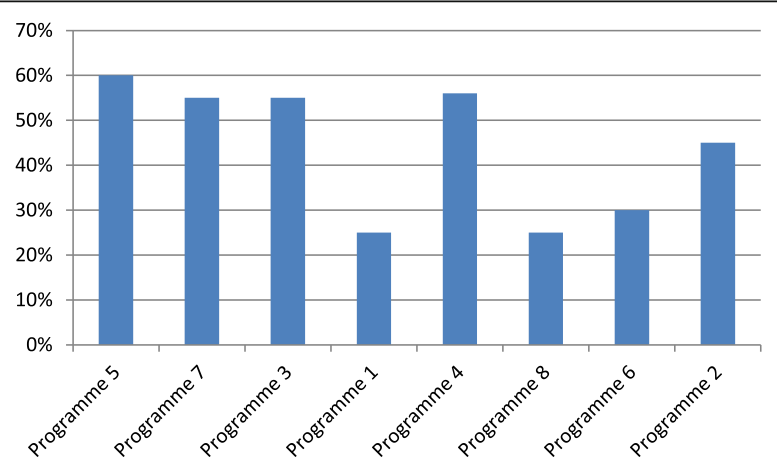

Fig. 1 Throughput of MPH programmes: students enrolled between 2009 and 2011 and graduated between 2012 and 2014 
The expansion of postgraduate public health training in SA developed in parallel with the advancement of the health system, fuelled by profound political changes that took place in SA in 1990s [34, 35]. The transition of SA to democracy in 1994 brought about health sector reforms and a new approach to health planning and health systems management. In 1997, a white paper for the transformation of the health system was promulgated, which called for the establishment of the district health system based on a primary health care approach [36]. The white paper also emphasized the need for a reorientation of health professional training, advocating for a strong focus in training on populationbased health planning, health promotion and education, and on the development of foundational public health functions [36]. In response to the call made by the white paper for the transformation of the health system, postgraduate public health training was then introduced. This led to the initial formation of three regional schools of public health offering $\mathrm{MPH}$ programmes, Gauteng (previously Transvaal), KwaZulu-Natal and Western Cape [34, 35].

The South African public health sector landscape has changed over the years and is in the process of implementing a National Health Insurance (NHI) and a re-engineering of primary health care. These initiatives require adequate human resources to support the health system at all levels [20]. Even though the HRH strategy highlights the need to upscale the number of public health professionals, the South African health system remains a curatively oriented health service [37, 38]. The allocation of resources focuses more on clinical services, with minimal attention given to health promotion and prevention [37, 38].

South Africa's public health history is rooted in fragmented and weak health system performance $[9,38]$. This is further exacerbated by the changing epidemiological transitions characterised by persistent infectious disease and emerging non-communicable disease burdens $[9,38,39]$. Effective leadership and stewardship is critical in improving the performance of the entire health system [3, 40]. The existing undersupply of public health professionals and shortfalls in the managerial and supervisory capacity is a threat to the success of a NHI scheme $[12,20]$. MPH programmes are viewed as potential contributors to address the current health system leadership deficiencies [13, 33, 41, 42]. However, the programmes might not be able to meet the need due to the lack of hands-on field practice within the training programmes. Factors contributing to the disconnection between public health leadership needs and what is taught may require further investigation.

Despite the rise in the number of public health programmes, the demand for public health postgraduate education seems to exceed what current MPH programmes can supply, both in terms of workplace demands for health professionals with public health competencies and in terms of rising student enrolments. One of the issues emerging for several MPH programmes is the inadequate number of academics, which puts an extra burden on existing staff. In addition, the number of staff with doctorates was inadequate for some MPH programmes which influences the "scholarship" in public health and public health training. The South African government is making efforts to enhance the qualifications of the academic staff, with the emphasis on doctoral training [43]. The paucity of academics with PhDs poses a challenge, given that the quality of higher education is not only determined by the number of staff but by their qualifications and research experience [44]. The staff shortages and scarcity of academics with PhDs have been reported in resource-poor countries and are largely attributable to the "brain drain" and small student enrolment numbers $[6,28,43-45]$. 
Public health competencies have been under scrutiny in a number of countries across the globe. In the USA, core public health competencies were established by the Council on Linkages between Academia and Public Health Practice in 2010. The Association of Schools in Public Health drafted a list in 2008, which was redefined in 2011 [46, 47]. The United Kingdom Public Health Skills and Career Framework was endorsed in 2008 [47, 48], whereas in Australia, the Foundation Competencies for MPH alumni were published in 2009 [49]. Professional competencies need to be context specific [47, 5052]. MPH graduates should possess and demonstrate skills and competencies in leadership, systems thinking, policy development, critical and analytical thinking, and teamwork and communication skills in order to improve health system performance and population health $[30,47,52,53]$.

Programmes need to identify core competencies for each curriculum domain [50, 51]. Core competencies for MPH programmes in SA have not been concluded. The current draft, under review by relevant stakeholders, outlines that MPH competencies should take into account the African health context which is characterised by epidemics of both communicable and non-communicable diseases [25].

The ailing health system and poor leadership and stewardship in the health sector, coupled with high burden of disease and emerging epidemics requires adequate and highly trained public health professionals [3, 34, 54]. The MPH programmes contribute to addressing competencies such as context-specific leadership, planning, and management [47]. Therefore MPH programmes in Africa should include competencies on leadership and health system strengthening [25].

The absence of an overarching body responsible for oversight of in SA ensuring benchmarking and standardization across programmes, is a challenge. There are countries that have a single independent council that covers conventional public health training for MPH programmes [37, 38]. Replicable models from those countries might assist in ensuring quality in public health training $[55,56]$. According to Fonn, a close partnership between the MPH programmes and national health systems must be established in order to ensure that public health training informs health systems planning and management [3].

Public health training is crucial in order to address the current discrepancies in HRH. However, the low throughput and delayed time to completion experienced by $\mathrm{MPH}$ programmes negatively affects the production of highly skilled practitioners for the health sector. The recommended 2 years for completing part time Master's programme is not always feasible for South African MPH students who are mostly mature students, in full time employment, and have other responsibilities [27, 57]. Therefore, MPH programmes need to devise strategies to assist students, especially when it comes to dissertation writing, which is reportedly when most students tend to delay or drop-out. Strategies could include cohort writing seminars and provide mentorship through alumni network and faculty staff as an on-going process for MPH students [57-59]. In addition, further research needs to be conducted to investigate factors contributing to student drop-out in MPH programmes.

\section{Limitations}

MPH programme coordinators that were interviewed all came from public universities who have offered the programme for more than 10 years. The two MPH programmes 
that did not participate are fairly new. There is one private institution that offers MPH training in South Africa. The perspectives of programme coordinators within the private institution may differ from programme coordinators that responded.

Based on the findings of this study and the literature cited, further research needs to be conducted on the development of a competency framework for MPH programmes in South Africa. Further research should focus on graduates' and employers' perspectives on the skills and competencies acquired from MPH programmes and how these impact the health sector. Furthermore, future studies will need to investigate the characteristics and career pathways of MPH graduates. Moreover MPH outputs and job match needs to be assessed.

\section{Conclusions}

$\mathrm{MPH}$ programmes are contributing to the public health training of the health workforce in South Africa. The increasing number of enrolments coupled by insufficient teaching personnel and low graduate output are key challenges impacting on the adequate production of health professionals with public health competencies. The absence of collaboration amongst the MPH programmes and the lack of standardization, quality assurance and benchmarking need considerable attention. Moreover, effective governance and investment in management development and research development (PhD graduates) are essential to strengthen the capacity of MPH programmes. This may result in adequate training of public health practitioners and overcome the current HRH constraints.

\section{Abbreviations}

HIV/AIDS: Human immunodeficiency virus/acquired immune deficiency syndrome; HRH: Human Resource for Health; MPH: Master of Public Health; NHI: National Health Insurance; NQF: National qualification framework; SA: South Africa

\section{Acknowledgements}

The authors would like to thank the MPH programme coordinators for participating in the survey. The contents of this article are solely the responsibility of the authors and do not necessarily represent the official views of the government.

\section{Funding}

This publication was made possible by grant number: R24TW008863 from the Office of the U.S. Global AIDS Coordinator and the U. S. Department of Health and Human Services, National Institutes of Health (NIH OAR and NIH ORWH).

Availability of data and materials

The datasets analysed during the current study available from the corresponding author on reasonable request.

\section{Authors' contributions}

TD had primary responsibility for the draft of the manuscript. TD, AV, RS and FS all contributed substantially to the intellectual content and finalization of the manuscript. All authors read and approved the final manuscript.

Competing interests

The authors declare that they have no competing interests.

\section{Consent for publication}

Not applicable

\section{Ethics approval and consent to participate}

Ethics approval was granted by the University of KwaZulu-Natal Human and Social Sciences Research Ethics Committee (HSS/0561/014D). Informed consent was obtained from all participating MPH programme coordinators.

\section{Author details}

${ }^{1}$ College of Health Sciences, School of Nursing and Public Health, Howard College Campus, University of KwaZulu-Natal, Glenwood, Durban, South Africa. ${ }^{2}$ College of Health Sciences, School of Nursing and Public Health, University of KwaZulu-Natal, Durban, South Africa. ${ }^{3}$ College of Humanities, School of Education, University of KwaZulu-Natal, Durban, South Africa. ${ }^{4}$ Department of Educational Development and Research, Faculty of Health, Medicine and Life Sciences, Maastricht University, Maastricht, Netherlands. 
Received: 31 August 2016 Accepted: 18 January 2017

Published online: 02 February 2017

\section{References}

1. Begg MD, Galea S, Bayer R, Walker JR, Fried LP. MPH education for the 21st century: design of Columbia University's new public health curriculum. Am J Public Health. 2014;104:30-6.

2. Sadana RCA, Petrakova A. Strenghthening public health education and training to improve global health. Bullettin of the World Health Organisation. 2007;85:163-4.

3. Fonn S. Linking public health training and health systems development in sub-Saharan Africa: opportunities for improvement and collaboration. J Public Health Policy. 2011;32:S44-51.

4. Sadana R, Petrakova A. Shaping public health education around the world to address health challenges in the coming decades. Bullettin of World Health Organisation. 2007;85:902-3.

5. Sanders D, Guwatudde D, Alexander L. Accessible public-health education: a potential growth area? Bullettin of the World Health Organisation. 2008;86:A-b.

6. Ijsselmuiden CBNT, Duale S, Tumwesigye NM, Serwadda D. Mapping Africa's advanced public health education capacity-the AfricaHealth project. Bullettin of the World Health Organisation. 2007:85:914-22

7. World Health Organisation. Working together for Health. Geneva: World Health Organisation; 2006

8. Dalton SC. The current crisis in human resources for health in Africa: the time to adjust our focus is now. Transactions of the Royal Society of Tropical Medicine Hygiene. 2014;108:526-7.

9. Mayosi BM, Lawn JE, van Niekerk A, Bradshaw D, Abdool Karim SS, Coovadia HM. Health in South Africa: changes and challenges since. Lancet. 2009;380:2029-43.

10. van Rensburg HC. South Africa's protracted struggle for equal distribution and equitable access—still not there. Human Resource for Health. 2014;12:26.

11. Elkhalifa GO. The current crisis in human resources for health in Africa. South Sudan Medical Journal. 2014;7:1-8.

12. National Department of Health. Human Resource for Health Strategy for the Health Sector: 2012/13-2016/17. Pretoria: National Department of Health; 2011.

13. Zwanikken P, Huong N, Ying X, Alexander L, Wadidi MS, Magana-Valladares L, Gonzalez-Robledo M, Qian X, Linh N, Tahir $\mathrm{H}$, et al. Outcome and impact of Master of Public Health programs across six countries: education for change. Human Resource for Health. 2014;12:40.

14. Alexander L, Igumbor E, Sanders D. Building capacity without disrupting health services: public health education for Africa through distance learning. Human Resource for Health. 2009;7:28.

15. Tulchinsky TH, Goodman J. The role of schools of public health in capacity building. Journal of Public Health. 2012:34:462-4

16. Mokwena K, Mokgatle-Nthabu M, Madiba S, Lewis H, Ntuli-Ngcobo B. Training of public health workforce at the National School of Public Health: meeting Africa's needs. Bullettin of the World Health Organisation. 2007;85:949-54

17. Evans D. The role of schools of public health: learning from history, looking to the future. J Public Health (Oxf). 2009:31:446-50.

18. Davis MV, Dandoy S, Greaves WW. Graduate programs: what is their contribution to the training of the public health workforce? American Journal of Preventative Medicine. 2003;24:361-6.

19. Hoffman MCD, Hodes R, London L. From comprehensive medicine to public health at the University of Cape Town: a 40 year journey. South African Medical Journal. 2012;102:442-446.

20. Lloyd B, Sanders D, Lehmann U. Human resource requirements for national health insurance. South African Health Review. 2010:1:171-178.

21. Nangami M, Rugema L, Tebeje B, Mukose A. Institutional capacity for health systems research in East and Central Africa schools of public health: enhancing capacity to design and implement teaching programs. Health Research Policy and Systems. 2014;12:22.

22. Tweheyo R, Nalwadda C, Ayebazibwe N, Mukanga D, Rutebemberwa E, Bazeyo W. Two decades of post-graduate training in applied public health: the experience and challenges of the Uganda Public Health School without walls. Pan Afr Med J. 2011:10:11.

23. Lloyd B, Sanders D, Lehmann U. Human resource requirements for National Health Insurance : perspectives on a national health insurance. 2010. p. 171-8. 171-178.

24. Department of Education. National plan for higher education. Pretoria: Goverment press; 2001. http://www. education.gov.za. Accessed 29 Mar 2016.

25. African Schools of Public Health Association. Core competencies for a Master of Public Health graduate in Africa. 2014

26. South African Qualifications Authority. The national qualifications framework and standards setting. 2000.

27. White F. The imperative of public health education: a global perspective. Medical Principles and Practice. 2013;22: 515-29.

28. Amde W, Sanders D, Lehmann U. Building capacity to develop an African teaching platform on health workforcedevelopment: a collaborative initiative of universities from four sub Saharan countries. Human Resource for Health. 2014;12:31.

29. Tucker JD, Cohen MS, PGDHHM KS, Jin-Ling Tang M. Public health education in India and China: history, opportunities, and challenges. Public Health Rev. 2011;33:204.

30. Mahat A, Bezruchka S, Gonzales V, Connell F. Assessment of graduate public health education in Nepal and perceived needs of faculty and students. Human Resource for Health. 2013;11:16.

31. Yach D, Tollman SM. Public health initiatives in South Africa in the 1940s and 1950s: lessons for a post-apartheid era. Am J Public Health. 1993;83:1043-50.

32. Longlett SK, Kruse J, Wesley R. Community-oriented primary care: historical perspective. The Journal of American Board of Family Practice. 2001;14:54-63.

33. Dlungwane T, Knight S. Tracking Master of Public Health graduates: linking higher education and the labour market: short research report. African Journal of Health Professions Education. 2016;8:132-4. 
34. Reddy J. Regional consortia, partnerships, mergers and thier implications for the transformation of the South African higher education system. Durban; 1998.

35. Gear J. Public health in South Africa 1975-89: reflections on a momentous past. Global Health Action. 2013;6. doi:10.3402/gha.v3406i3400.20095.

36. Pick W. Reflections on Public Health in South Africa, 1993-2002. Global Health Action. 2013;6. doi:10.3402/gha. v3406i3400.20094

37. National Department of Health. White Paper for the Transformation of Health System in South Africa. Pretoria: National Department of Health; 1997.

38. Kautzky K, Tollman SM. A perspective on primary health care in South Africa. South African Health Review. 2008;1: $17-30$.

39. Zweigenthal V, London L, Pick W. The contribution of specialist training programmes to the development of a public health workforce in South Africa. South African Health Reviews. 2016;1:45-59.

40. Mayosi BM, Benatar SR. Health and health care in South Africa-20 years after Mandela. N Engl J Med. 2014;371:1344-53.

41. Coovadia H, Jewkes R, Barron P, Sanders D, Mclntyre D. The health and health system of South Africa: historical roots of current public health challenges. The Lancet. 2009;374(9692):817-34.

42. National Department of Health: Human Resource for Health South Africa. 2011. http://www.health.gov.za. Accessed 20 Mar 2016.

43. Zwanikken PA, Alexander L, Scherpbier A. Impact of MPH programs: contributing to health system strengthening in low- and middle-income countries? Human Resource for Health. 2016;14:52.

44. Academy of Science of South Africa. The PhD Study. An Evidence-based Study on how to meet the Demands for Higher-level Skills in an Emerging Economy Pretoria: 2010. http://www.assaf.org.za. Accessed 10 Sept 2014.

45. Tettey WJ. Challenges of developing and retaining the next generation of academics: deficits in academic staff capacity at African universities. New York: Partnership for Higher Education in Africa; 2010:1-114.

46. Rabbani F, Shipton L, White F, Nuwayhid I, London L, Ghaffar A, Ha BTT, Tomson G, Rimal R, Islam A. Schools of public health in low and middle-income countries: an imperative investment for improving the health of populations? BMC Public Health. 2016;16:941.

47. Moser JM. Core academic competencies for Master of Public Health Students: one health department practitioner's perspective. Am J Public Health. 2008;98:1559-61.

48. Zwanikken P, Alexander L, Huong N, Qian X, Valladares L, Mohamed N, Ying X, Gonzalez-Robledo M, Linh L, Wadidi MS, et al. Validation of public health competencies and impact variables for low- and middle-income countries. BMC Public Health. 2014;14:55.

49. Wright J, Rao M, Walker K. The UK public health skills and career framework—could it help to make public health the business of every workforce? Public Health. 2014;122:541-4.

50. Genat B, Robinson P. New competencies for public health graduates: a useful tool for course design. Aust N Z J Public Health. 2010;34:513-6.

51. Zodpey SP, Negandhi H, Yeravdekar R. Future directions for public health education reforms in India. Frontiers in public health. 2014;2:68.

52. Negandhi H, Negandhi P, Tiwari R, Sharma A, Zodpey S, Kulatilaka H, Tikyani S. Developing core competencies for monitoring and evaluation tracks in South Asian MPH programs. BMC Med Educ. 2015;15:126.

53. Frenk J, Chen L, Bhutta ZA, Cohen J, Crisp N, Evans T, Fineberg H, Garcia P, Ke Y, Kelley P, et al. Health professionals for a new century: transforming education to strengthen health systems in an interdependent world. Lancet. 2010;376:1923-58.

54. Williams JR, Schatz EJ, Clark BD, Collinson MA, Clark SJ, Menken J, Kahn K, Tollman SM. Improving public health training and research capacity in Africa: a replicable model for linking training to health and sociodemographic surveillance data. Global Health Action. 2010;3.

55. Whitworth JAG, Kokwaro G, Kinyanjui S, Snewin VA, Tanner M, Walport M, Sewankambo N. Strengthening capacity for health research in Africa. Lancet. 2008;372:1590-3.

56. Birt CA, Anders Foldspang M. The developing role of systems of competences in public health education and practice. Public Health Rev. 2011;33:134.

57. Linda Rosenstock M, Helsing K. Public health education in the United States: then and now. Public Health Rev. 2011;33:39.

58. Dlungwane T, Voce A, Searle R, Wassermann J. Understanding student early departure in a Master of Public Health (MPH) programme in South Africa. African Journal of Health Professions Education. 2016. (Accepted for Publication).

59. Dlungwane T,Voce A, Searle R, Stevens F. Exploring student persistence in a Master of Public Health programme: a qualitative study. University of KwaZulu-Natal; 2016. Durban. 